\title{
Effect of Different Ethephon Concentrations on Shiss Removal in 'Khlass' and 'Sukkary' Date Palm Varieties
}

\author{
Abdelazize Eljiati ${ }^{1 *}$, Imtiaz Ahmed ${ }^{1}$, Naoki Terada ${ }^{2}$, Atsushi Sanada ${ }^{2}$, Kaihei Koshio $^{2}$ \\ ${ }^{1}$ Yousef Bin Abdul Latif and Sons Agriculture Co. Ltd. Research and Development Departnment., Al-Shihiyah \\ 52758, Gassim, Saudi Arabia; ${ }^{2}$ Tokyo University of Agriculture, Dept. of International Agricultural Development, \\ Laboratory of Tropical Horticultural Science. 1-1-1 Sakuragaoka, Setagaya, Tokyo, 156 8502, Japan.
}

Received: December 4, 2021 / Accepted: February 28, 2022

\begin{abstract}
After pollination, aborted date fruits known as tricarpel or shiss, remain on the bunch in most of the varieties and exert a competition on fruits for water and nutrients. In Sukkary, they drop down at the end of kimri stage, while remain on 'Khlass' until the harvest. Most of them remain as bisr and little turns into tamr that is not appreciated in the date market. They can only be used as paste that has low price compared to dates. In an attempt to get rid of shiss, we sprayed Ethephon at different concentrations on bunches of 'Sukkary' and 'Khlass' after fruit-set, at hababook stage. Beside the shiss drop, undesirable fruit drop also occurs. We are looking for the optimum Ethephon concentration where shiss dropped more than fruits. In 'Khlass', the Ethephon concentration $800 \mathrm{ppm}$ showed the highest shiss drop (81\%) together with a fruit drop of $20 \%$ that occurs at the same time, while in 'Sukkary', the concentration of $600 \mathrm{ppm}$ was the best by giving a shiss drop equal to $44 \%$ together $12 \%$ fruit drop. We consider that the concentration of $800 \mathrm{ppm}$ at hababook stage is the ideal concentration to generate optimum drop in shiss with reasonable percentage of fruit drop. We, therefore highly recommend a trial with this concentration on 'Sukkary' as well.
\end{abstract}

Keywords: Abortion, Shiss, Date palm, Fruit, Ethephon.

*Corresponding author: a.eljiati@gmail.com

\section{Introduction}

The Ethephon or the 2-chloroethylphosphonic acid (CEPA) is a systemic plant growth regulator, which in its liquid state at the proper $\mathrm{pH}$ does not yield ethylene; however, when the $\mathrm{pH}$ is elevated, it breaks down to form ethylene (Arteca, 1996). However, at $\mathrm{pH}$ higher than 4 , it breaks down to ethylene, hydrochloric and phosphatic ions. It stimulates the endogenous ethylene production by releasing ethylene in the plant tissue as the cell cytoplasm has a pH higher than 4 (Nicotra, A. 1982).

The main role of ethylene is to make changes in fruit texture, softening, colour, and other processes involved in ripening. It is also known as the aging hormone in plants. It is well known that Ethephon can promote fruit abscission. Ethephon has been performed well as a fruit-thinning agent for many crops (Abeles et al., 1992). Ebert and Bangerth (1982) reported that ethylene inhibited the synthesis and translocation of Indole-3-Acetic Acid (IAA) within the fruits, thus reducing sink strength and ultimately inducing the separation area in the peduncle, which causes fruit drop (Roberts et al. 2002.).

El Hamadi et al. (1983) used Ethephon at different concentrations from 200 to $400 \mathrm{ppm}$ after fruit set and deduced that the level of thinning increased by increasing the concentration.

Mohamed et al (2015) concluded that Ethephon at 1000 ppm, ten days after pollination are

This is an Open Access article distributed under the terms of the Creative Commons Attribution

License (http://creativecommons.org/licenses/by/3.0/), which permits unrestricted use, distribution, 
suitable for obtaining economic yield with best fruit quality.

Bakr et al. (2006) tested the effect of Ethephon on fruit thinning compared with cytophex at different concentrations and dates of application on 'Samany' date palm variety. They concluded that, 'Samany' fruit set was decreased when Ethephon was sprayed 18 days after pollination especially at $300 \mathrm{ppm}$.

No study has been done before on the use of Ethephon in order to remove aborted date fruits known as tri-carpel or shiss that remain on the bunch and compete on fruits for water and nutrients. That was the objective of this investigation.

\section{Materials and Methods}

Location of the experiment: This trial was carried out in the Experimental farm "Naam" of Yousef Bin Abdul Latif and Sons Agriculture Co. Ltd. (YALA) in Qassim, Saudi Arabia.

The weather conditions of the farm during the 12 days of the experiment on each of the two date varieties 'Sukkary' and 'Khlass' are summarized in the Figures 1 and 2 as recorded by the weather station of the farm.

For 'Sukkary', during the 12 days of study (6-18 May 2019), the reference evapotranspiration (ET0)
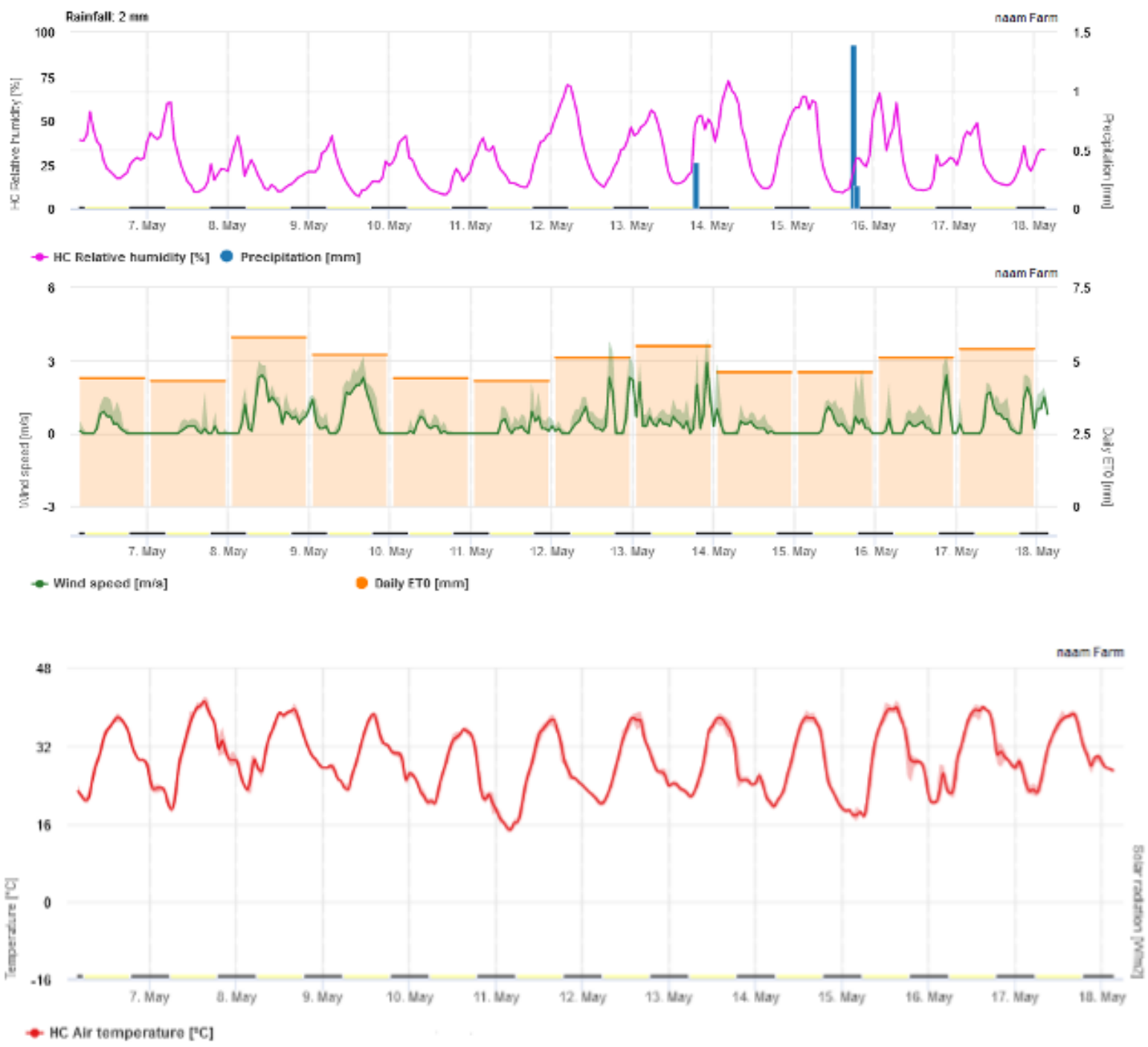

Figure 1. Weather conditions of the experimental farm during the 12 days of study on 'Sukkary' variety (from 6 to 18 May 2019). 


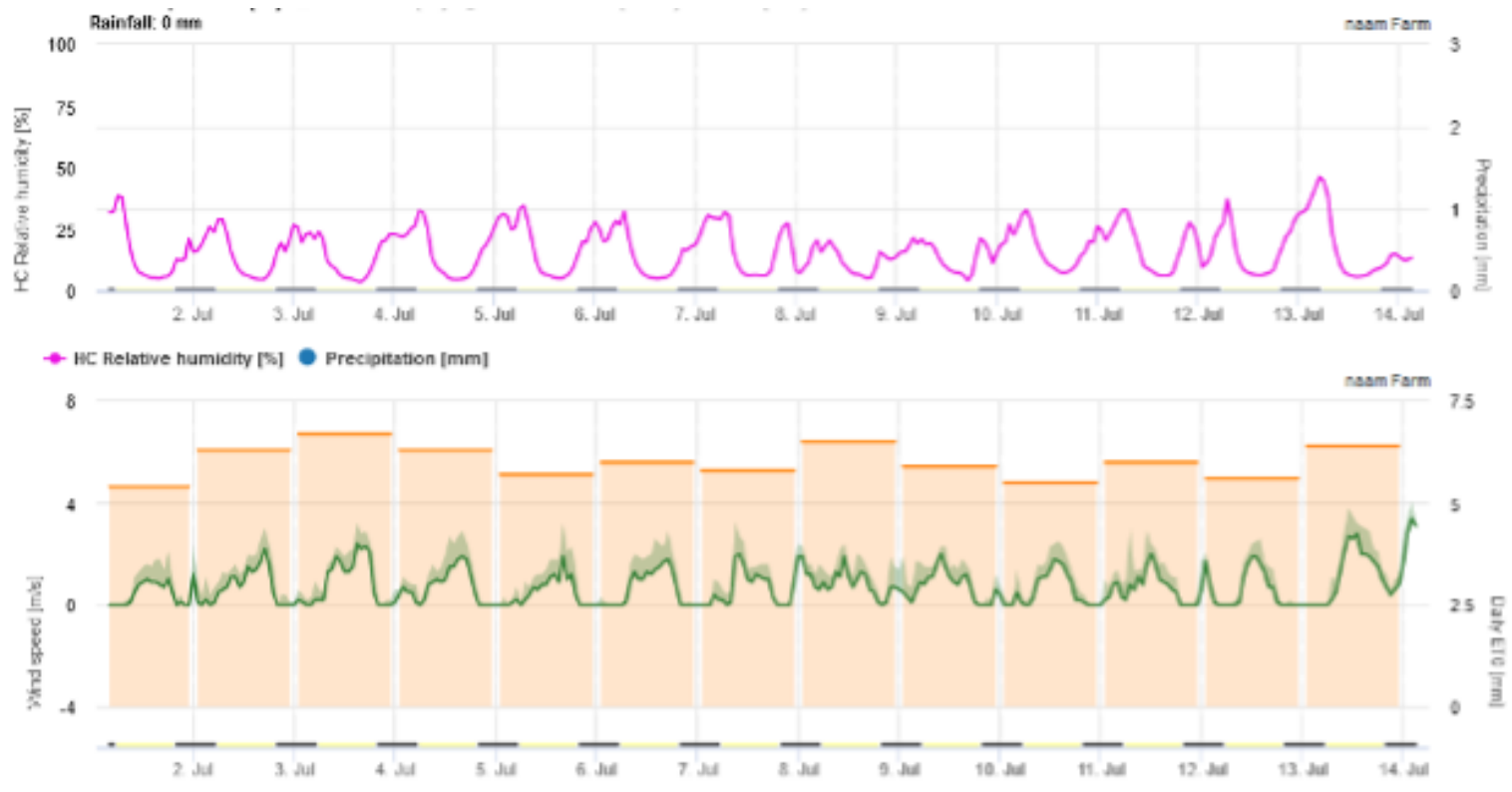

- Wind speed [mis] 0 Oaily ETo [mm]

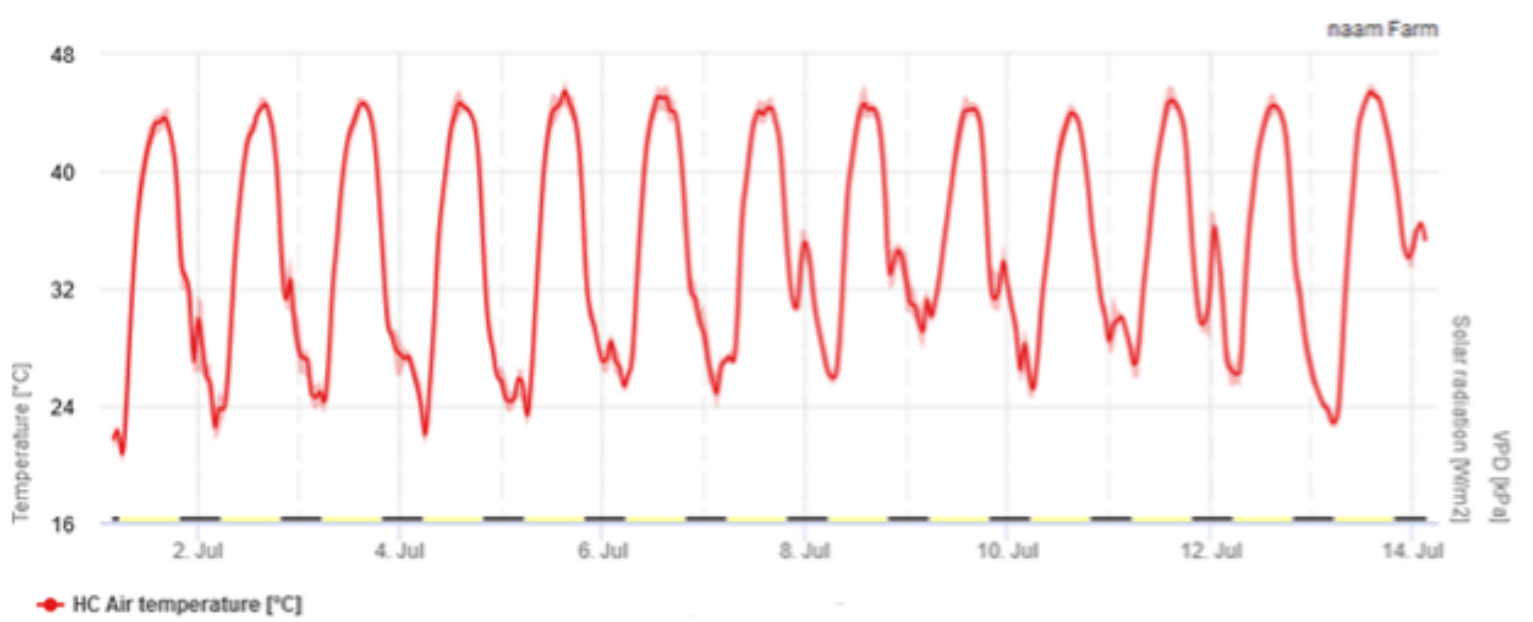

Figure 2. Weather conditions of the experimental farm during the 12 days of study on 'Khlass' variety (from 2 to 14 July 2019).

ranged between 4.3 and $5.8 \mathrm{~mm}$ day- 1 , the cumulative precipitation was $2 \mathrm{~mm}$ and the maximum wind speed was $5.5 \mathrm{~m} / \mathrm{s}$. The maximum temperature recorded during the day ranged between 35.4 and $41.2{ }^{\circ} \mathrm{C}$ (Figure 1).

For 'Khlass' variety, during the 12 days of study (2-14 July 2019), the reference evapotranspiration (ET0) ranged between 5.4 to $6.7 \mathrm{~mm}$ day-1, there was no precipitations during this period, and the maximum wind speed was $3.3 \mathrm{~m} / \mathrm{s}$. The maximum temperature recorded during the day ranged between 43 and $45.5^{\circ} \mathrm{C}$ (Figure 2).

The Experiment: The spray started first on 'Sukkary', as it is an early maturing variety, then on 'Khlass'. 'Sukkary' was sprayed on 6 May 2019 and the evaluation was done 12 days later on 18 May 2019. 'Khlass' was sprayed on 2 July 2019 and the evaluation was done 12 days later on 14 July 2019.

The concentrations of Ethephon applied on 'Sukkary' were: 1000 ppm, 600 ppm and 400 ppm in addition to the control where only pure water is sprayed. After evaluation of results on 'Sukkary', we changed the concentrations on 'Khlass' to respectively $1000 \mathrm{ppm}, 800 \mathrm{ppm}, 600 \mathrm{ppm}$ in addition to pure water as a control.

Three trees per variety have been used for this experiment. One bunch per tree per treatment was sprayed. We have in total three bunches per treatment.

Before the spray, the total number of fruits and shiss were counted. After the spray, the bunches are 
a)

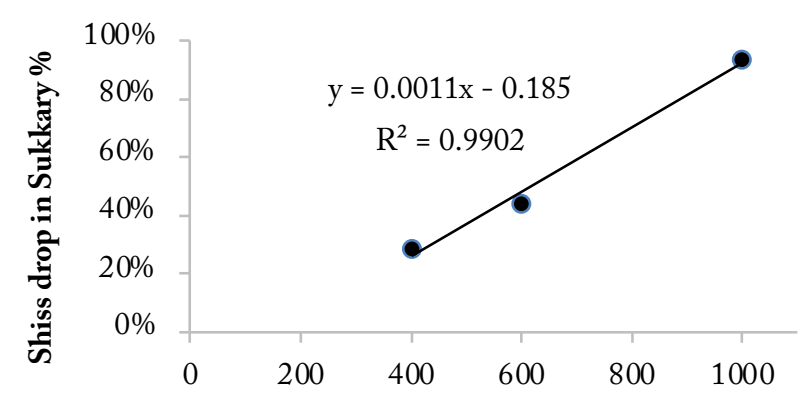

Ethephon concentration in ppm

b)

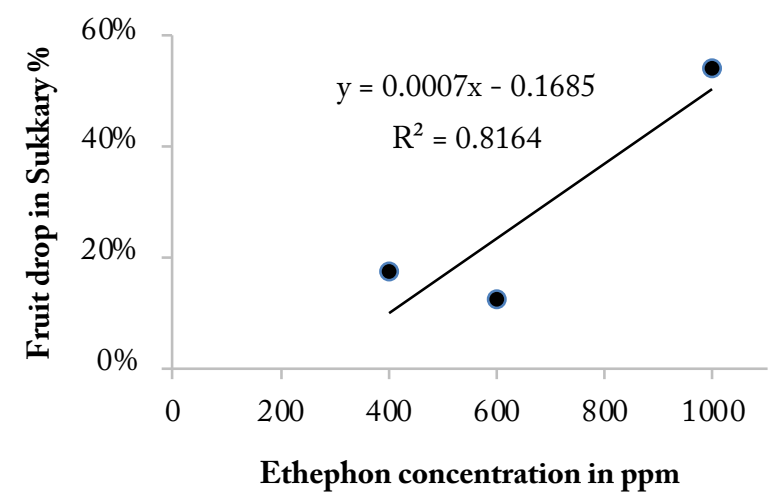

Figure 3. Correlation between the Ethephon concentration and the percentage of shiss (a) and fruit drop (b) generated in 'Sukkary' date variety.

covered with a bunch bag (a mesh bag) to collect dropped shiss and fruits.

Fruits and shiss remaining on the bunches are counted 12 days after the spray. Dropped fruits and shiss are calculated as follow:

Number of dropped fruits $=$ IFN - FFN

Number of dropped shiss $=$ ISN - FSN

Where:

IFN : Initial fruit number on the bunch before spray FFN : Final fruit number on the bunch 12 days after spray

ISN: Initial shiss number on the bunch before spray

FSN : Final shiss number on the bunch 12 days after spray

The percentage of fruits and shiss dropped from the total initial number existing before the spray is calculated as follow:

Percentage of fruit drop (\%) = Number of dropped fruits / Number of fruits on the bunch before the spray

Percentage of shiss drop $(\%)=$ Number of dropped shiss / Number of shiss on the bunch before the spray

\section{Results and Discussion}

When bunches of 'Sukkary' were sprayed with 1,000 ppm of Ethephon, $94 \%$ of shiss dropped together with $54 \%$ of fruits (Table 1). At $600 \mathrm{ppm}$ Ethephon, $44 \%$ of the shiss dropped, against $12 \%$ of fruit drop. At the concentration of $400 \mathrm{ppm}$ Ethephon, $28 \%$ of the shiss dropped and $17 \%$ of fruits. For the control where pure water is sprayed on the bunches, $4 \%$ of the shiss dropped, together with $8 \%$ of fruit drop.

The concentration of 1,000 ppm Ethephon, despite generating a desirable high shiss drop, significantly different from the one generated by the concentration of $600 \mathrm{ppm}$ Ethephon, but it did unfortunately the same for fruit drop (Table 1). This is why we recorded a high correlation between Ethephon concentration from one side and shiss drop $\left(R^{2}=0.9902\right)$ and fruit drop percentages $\left(R^{2}=0.8164\right)$ from the other side (Figure 3 ). Therefore, we have to look for an optimal concentration of Ethephon that generates a significant increase in shiss drop with a 
Table 1. Percentage of drop generated in fruits and shiss of 'Sukkary', 12 days after spray by Ethephon at different concentrations.

\begin{tabular}{|c|c|c|c|c|}
\hline & \multicolumn{3}{|c|}{ Ethephon Concentration } & \multirow{2}{*}{$\begin{array}{c}\text { Control } \\
\text { (Pure Water) }\end{array}$} \\
\hline & 1000 ppm & 600 ppm & 400 ppm & \\
\hline Percentage of shiss drop (\%)* & $94 \% \mathrm{a}$ & $44 \% \mathrm{~b}$ & $28 \% \mathrm{c}$ & $4 \% \mathrm{~d}$ \\
\hline Percentage of fruit drop (\%) ${ }^{* *}$ & $54 \%$ a & $12 \% \mathrm{~b}$ & $17 \% \mathrm{~b}$ & $8 \% \mathrm{c}$ \\
\hline
\end{tabular}

(*) Averages of shiss drop (\%) that do not share the same letter are significantly different according to T-test analysis.

${ }^{* *}$ ) Averages of fruit drop (\%) that do not share the same letter are significantly different according to $T$-test analysis.

Table 2. Percentage of drop generated in fruits and shiss of 'Khlass', 12 days after the spray by Ethephon at different concentrations.

\begin{tabular}{|c|c|c|c|c|}
\hline & \multicolumn{3}{|c|}{ Ethephon Concentration } & \multirow{2}{*}{$\begin{array}{c}\text { Control } \\
\text { (Pure Water) }\end{array}$} \\
\hline & 1000 ppm & 800 ppm & 600 ppm & \\
\hline Percentage of shiss drop (\%)* & $89 \%$ a & $81 \%$ a & $64 \% \mathrm{~b}$ & $4 \% \mathrm{c}$ \\
\hline Percentage of fruit drop (\%) *** & $37 \%$ a & $20 \% \mathrm{~b}$ & $24 \% \mathrm{~b}$ & $0 \% \mathrm{c}$ \\
\hline
\end{tabular}

(*) Averages of shiss drop (\%) that do not share the same letter are significantly different according to T-test analysis. $\left.{ }^{* *}\right)$ Averages of fruit drop (\%) that do not share the same letter are significantly different according to T-test analysis.

a)

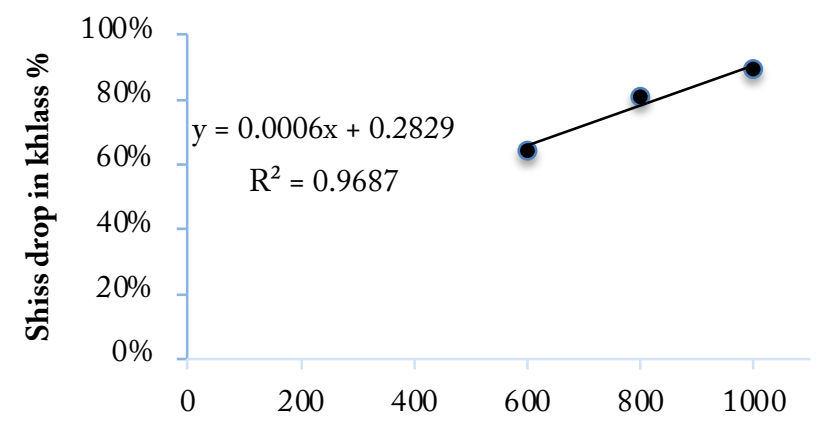

Ethephon concentration in ppm

b)

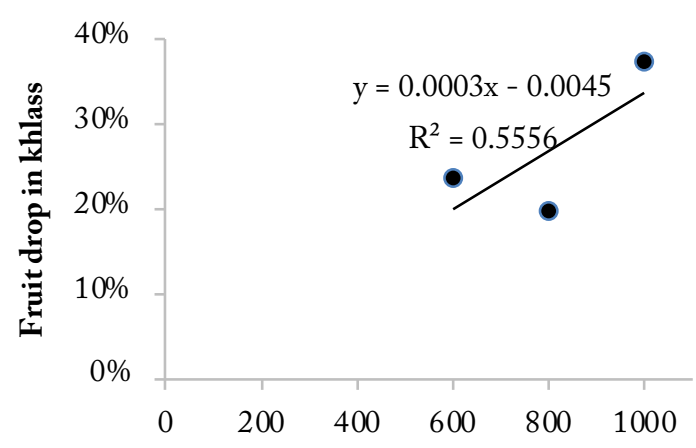

Ethephon concentration in ppm

Figure 4. Correlation between the Ethephon concentration and the percentage of shiss (a) and fruit drop (b) generated in 'Khlass' date variety. 
lower percentage of fruit drop. It seems that an Ethephon concentration between 1000 ppm and 600 ppm (800 ppm for example) might be the optimal concentration to be tried in order to get more shiss drop and at the same time less fruit drop. For this reason, we replaced the concentration $400 \mathrm{ppm}$ of Ethephon by $800 \mathrm{ppm}$ in the same season on the next experiment on 'Khlass' that flowers after 'Sukkary'.

On the other hand, when bunches of 'Khlass' are sprayed with 1,000 ppm of Ethephon, a total of 89\% of shiss dropped together with $37 \%$ of fruits (Table 2). At 800 ppm Ethephon, 81\% of shiss dropped, which is not significantly different from shiss percentage dropping in the case of $1000 \mathrm{ppm}$ Ethephon. The concentration 800 ppm Ethephon also generated 20\% of fruit drop, similar statistically to the fruit dropping in the case of $600 \mathrm{ppm}$ Ethephon (24\%). At the concentration of $600 \mathrm{ppm}$ Ethephon, $64 \%$ of the shiss dropped and $24 \%$ of fruits. For the control where pure water is sprayed on the bunches, $4 \%$ of the shiss dropped, with no drop recorded in the fruits.

In 'Khlass', the Ethephon concentration 800 ppm showed the optimum drop between shiss (81\%) and fruits $(20 \%)$, as it generated similar shiss drop percentage generated by the highest Ethephon concentration (1000 ppm) and kept an undesirable fruit drop percentage (20\%) similar to the one generated by the lower $600 \mathrm{ppm}$ Ethephon concentration (24\%).

This has been translated by a strong correlation between Ethephon concentration and shiss drop $\left(\mathrm{R}^{2}=\right.$ 0.9687) (Figure 4a) and a low correlation between Ethephon concentration and fruit drop $\left(R^{2}=0.5556\right)$ (Figure 4b).

In a chemical thinning experiment, Mohamed et al. (2015) sprayed Ethephon ten days after pollination (10 DAP) at 500 and 1,000 ppm on 'Khlass' and 'Ruzeiz' date varieties. When the evaluation is made after two months from pollination, they found out that the fruit drop in both 'Khlass' and 'Ruzeiz' was not concentration-dependant. They reported a fruit drop in 'Khlass' equal to $45.5 \%$ and $38.6 \%$ respectively for $500 \mathrm{ppm}$ and $1000 \mathrm{ppm}$ of Ethephon and in 'Ruzeiz' equal to $16.3 \%$ and $17.9 \%$ respectively for $500 \mathrm{ppm}$ and 1,000 pm of Ethephon. The effect of the increase in their Ethephon concentration was only seen at the harvest when they evaluated the fruits retained on the bunch, which was in 'Khlass' 63.9\% and 44.9\% respectively for the treatment $500 \mathrm{ppm}$ and $1000 \mathrm{ppm}$ of Ethephon and was in "Ruzeiz" 77.1\% and 62.5\% respectively for the treatment $500 \mathrm{ppm}$ and $1,000 \mathrm{ppm}$ of Ethephon.
Ghazzawy et al., (2019), concluded on 'Khlass' that the Ethephon applied at different concentrations 5 days after pollination (DAP) generated an average of $42.1 \%$ of fruit drop against $43.4 \%$ when applied 10 days after pollination. They also reported in both application times that the greater the concentration of Ethephon is, the lower the fruit drop becomes. When the Ethephon is applied $5 \mathrm{DAP}$, the fruit drop is $50.1 \%, 40.2 \%, 35.8 \%$ and $36 \%$ respectively for the control, $100 \mathrm{ppm}, 200 \mathrm{ppm}$ and $300 \mathrm{ppm}$ of Ethephon.

\section{Conclusion}

To remove aborted fruits of date palm (known as tri-carpel or shiss) that remain on the brunch and exert a competition for water and nutrients, we sprayed Ethephon in hababook stage at different concentrations on bunches of 'Sukkary' and 'Khlass' varieties.

In 'Khlass', the Ethephon concentration 800 ppm showed the optimal drop (more shiss and less fruits) equal to $81 \%$ in shiss and $20 \%$ in fruits. While in 'Sukkary', the concentration of $600 \mathrm{ppm}$ was the optimal with a shiss drop equal to $44 \%$ and fruit drop equal to $12 \%$.

We consider that the concentration of $800 \mathrm{ppm}$ at hababook stage might be the ideal concentration to generate optimal drop in shiss with reasonable percentage of fruit drop. We, therefore highly recommend a trial using this concentration on 'Sukkary'.

\section{Acknowledgements}

The authors would like to deeply thank Mr Youssef Jameel the Chairman of Yousef Bin Abdul Latif and Sons Agriculture Co. Ltd for his financial support and for allowing us to use the farm and laboratory facilities of his Company during this research.

\section{References}

Abeles FB, PW Morgan, and ME Saltveit Jr. (1992) Ethylene in Plant Biology,2nd ed. Academic Press, San Diego, CA, pp. 264-296.

Arteca RN (1996) Historical aspects and fundamental terms and concepts. In R. N. Arteca (Ed.), Plant growth substances: Principles and applications (pp. 1-27). New York, NY: Chapman \& Hall.

Bakr EI, GM Haseab, S EL-Kosary, and TY Saber (2006) Effect of chemical fruit thinning of Samany 
date palm cultivar. J. Agric. Sci. Mansoura Univ., 31 (10): $6385-6407$.

Ebert A and F Bangerth (1982) Possible hormonal mode of action of three apple thinning agents. Sci. Hort. 16:343-356.

El Hamadi M, K Ahmed, and AA El Hamadi (1983) Fruit thinning using Ethephon. Proceedings of the First Symposium on the Date Palm. College of the Agricultural Sciences and Food. King Faisal University El Hassa, Saudi Arabia. pp: 284-295.

Ghazzawy HS, MR Alhajhoj, AA Sallam, and M Munir (2019) Impact of chemical thinning to improve fruit characteristics of date palm cultivar Khalas. Iraqi J. of Agri. Sci. 50 (5): 1361-1368.

Al Saikhan MS, and AA Sallam (2015) Impact of chemical and non-chemical thinning treatments on yield and fruit quality of date palm. J Food Res 4 (4): 18-29. https://doi.org/10.5539/jfr.v4n4p18.

Nicotra A (1982) Growth regulators in pear production. Acta Hort. 124: 131-148.

Roberts JA, KA Elliot, and ZH Gonzales-Carranza (2002) Abscission, dehiscence and other cell separation processes. Ann. Rev. Plant Biol. 53: 131-158. 